\title{
$\cdots-\cdot$
}

\section{THE SILVA} METHOD

\section{Are you looking to change your life? Pam Swain' explains how the Silva Method can help you to do just this.}

May the rest of your life be the best of your life' Jose Silva 1914-1999

The Silva Method began in Laredo, Texas in the 1940s when Jose Silva whose interest in psychology began in the US Signals Corps during WWII - began to seek ways to help his children with their homework and to develop their concentration.

\section{Author information}

'Pam Swain MBA LCGI FIAM FCMI is the Chief Executive of the British Association of Dental Nurses (BADN) and Editor of the British Dental Nurses' Journal; in her other life, she is an AMTA-certified massage therapist (MINE, Cambridge MA, 1991), an accredited facilitator for 'Heal Your Life' workshops, a Silva Graduate, and is also certified in stress management, on-site massage and Reiki.
Over the next ten years, his children began to concentrate better, their memories improved but they also began to develop their intuition. Jose Silva then began to train small groups of neighbouring children, and adults, until he was asked to share his research with a group of artists in Armarillo in 1966. From this, the Silva Method programme was born - taught first throughout the United States, and then to other countries, being translated into dozens of other languages including Spanish, Mandarin, French, Korean, Italian, Japanese, Greek, Russian, Portuguese and Hungarian.

The human brain is made up of around 100 billion neurons which continuously fire energy and then rest. The number of times per second they fire and rest is known as their frequency. Generally speaking, whilst you are awake and active, the predominant frequency is around 20 cycles per second - what is known as the beta frequency. If you are very relaxed, or just falling asleep, the predominant frequency is slower at between seven and 14 cycles per second - or the alpha frequency. If you practise some meditation techniques, such as Transcendental Meditation (TM), your brain will reach even slower cycles, theta and delta - delta being the slowest cycle usually reached during deep sleep.

Children function mostly at delta until the age of four, and then from ages four to seven, mostly at theta. Around the age of seven, children switch to mostly alpha until their early teenage years when the beta frequency, associated with the left brain hemisphere, becomes predominant and continues to be so for the rest of their lives.

The left brain hemisphere is associated with logical thought and physical experience whilst the right brain hemisphere is more visual and processes intuitively, holistically and randomly. In most people, the left brain hemisphere is dominant and they no longer consciously use the alpha brain frequency.

'The discovery that human intelligence can learn to function with awareness at the alpha and theta brain frequencies will go down in history as the greatest discovery of man. This discovery has already started to change our concepts of the mind, psychology, psychiatry, psychoanalysis, hypnoanalysis and of the subconscious' Jose Silva 
The Silva Method aims, by way of meditation and other techniques, to teach students how to use the alpha level consciously and to use both brain hemispheres. It has no religious connotations and is practised worldwide by people of every, or no, faith. At the alpha level, one is able to think creatively with the right brain, whilst maintaining logic and rationality via the left brain, thereby improving concentration, developing intuition, creativity, and memory. This, Silva Grads will tell you, leads to improvements in setting and achieving goals, in studying, health and healing, memory, and in learning ability - in most areas of life in fact!

I completed the Basic Silva course led by an inspiring lady called Velores Figures in the late 1980s whilst living in Bermuda, and then completed the Ultimate course in Laredo with Jose Silva himself in 1990. I attended the Basic course in Bermuda at the insistence of my Bermudian flatmate - an enthusiastic New Age type who was very into meditation, crystals, self-development and so on ... as a straightforward Lancashire lass, I was decidedly sceptical!

\section{Karin Barnes - Certified Silva Method Instructor (CSMI)}

Karin first became a Silva Method Graduate in 1993 and then became a Certified Silva Method Instructor in 2004 and regularly presents the Silva Life System and the Silva Intuition System classes in UK.

Karin says 'I have seen so many people over the years change their lives after attending the course, who then go on to do great things for themselves and for others, to make this an even better world to live in. I feel very privileged to share Jose Silva's course with such inspiring, motivated and caring people.'

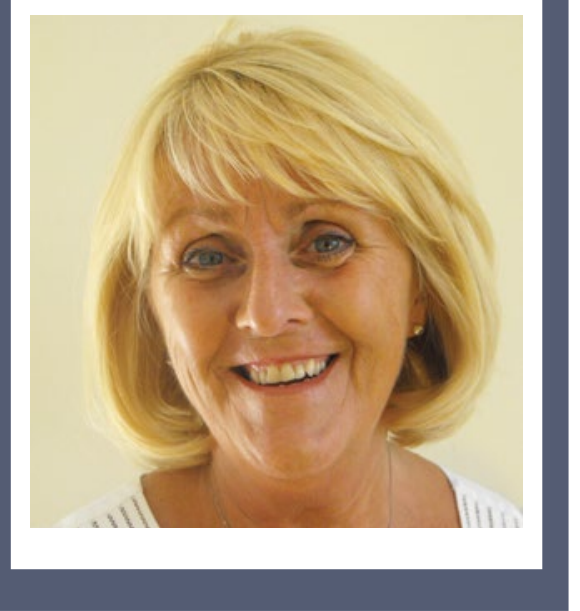

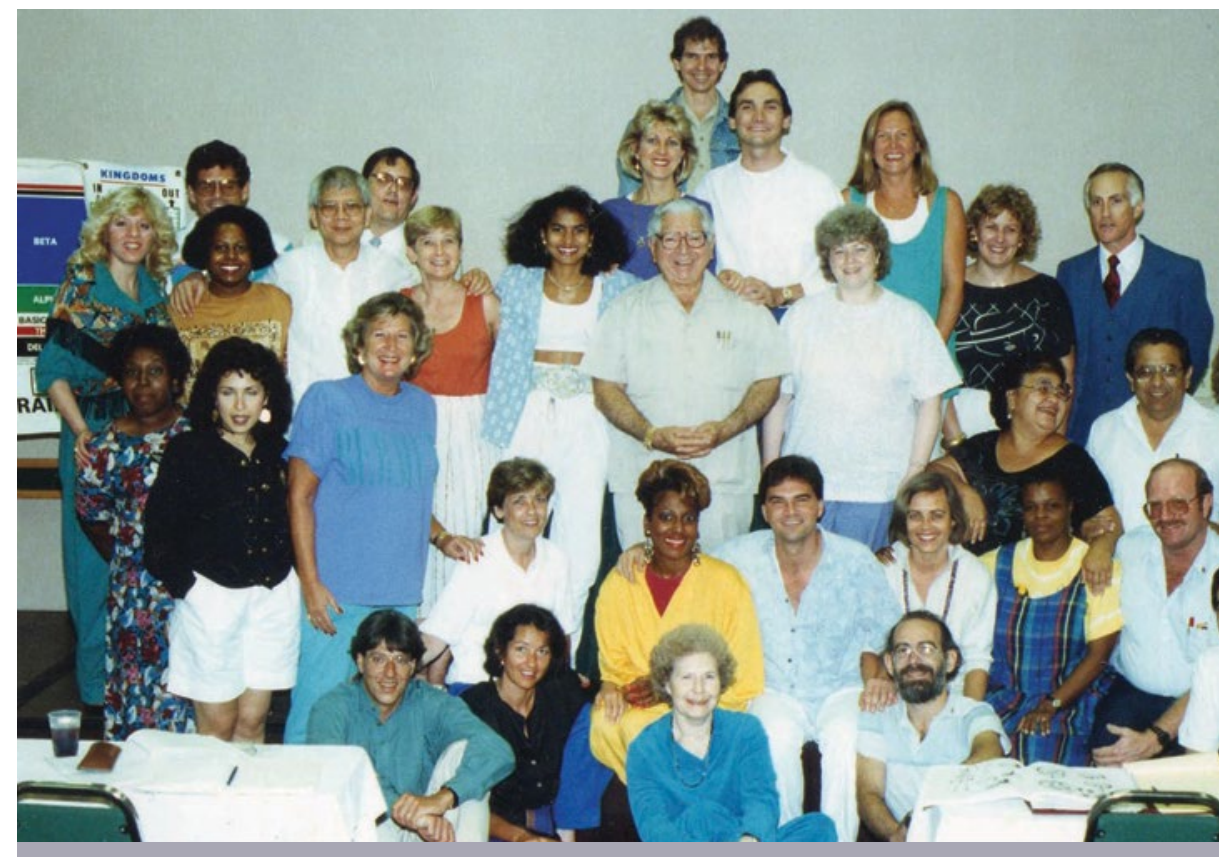

Silva Ultimate Class - Laredo, Texas, August 1990. Jose Silva is in the centre in a white suit. Can you spot Pam?

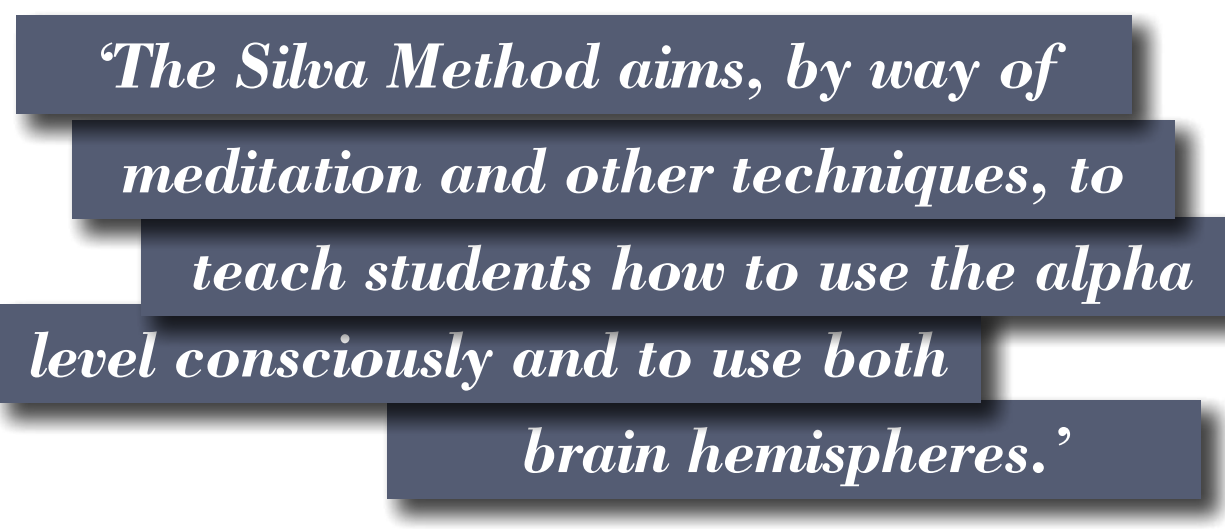

My right hand was at the time slightly incapacitated - not enough to cause problems, but enough to be an occasional nuisance - due to an accident a few years earlier which had led to 30 stitches in the palm of my hand. The heel of my hand had been pulled together tightly during stitching, and I couldn't flatten my hand out. At that time, you could attend the first day of a course and, if you didn't feel it was for you, you could leave and not pay and, to be honest, that's what I had intended to do, just to keep the peace with my flatmate. Imagine my amazement, when, by the end of the day, I discovered the adhesions in my hand stretching and that I was now able to spread my hand flat on the table!

The Ultimate course I completed in 1990, just before moving to Boston, Massachusetts, to undertake a year long AMTA massage therapy qualification. The techniques I learned helped greatly, not only with the theory study (learning anatomy and physiology at 32, 14 years after leaving school was made much easier with the Three Fingers Technique!) but also with the practical, where the newly developed intuition meant I was a star pupil at locating problem areas.

Until recently, courses in this country were either held in London in Hungarian (apparently it is very popular in Hungary!) or in Peterborough, which is not the most accessible place from the North West. But one of the silver linings of lockdown has been the emergence of Zoom; Silva lecturer Karin Barnes, in May this year, held the first UK Zoom Silva course. Any Silva graduate can repeat the course anytime, anywhere in the world, either for free or on payment of a small admin fee, so I repeated with Karin - along with students from India, Germany, Holland and Mauritius... the wonder of technology! And things are just getting 'Better and Better'!

For more information on the Silva Method, visit www.silvamethod.uk.com or www.karinbarnes.co.uk. Jose Silva's books, including You The Healer: The World-Famous Silva Method on How to Heal Yourself and Others are available from Amazon. 